\title{
SEVERIDADE DA ANTRACNOSE E QUALIDADE DOS FRUTOS DE MARACUJÁ-AMARELO TRATADOS COM PRODUTOS NATURAIS EM PÓS-COLHEITA ${ }^{1}$
}

\author{
ANTÔNIO JUSSIÊ DA SILVA SOLINO², SEBASTIÃO ELVIRO DE ARAÚJO NETO², \\ ALISSON NUNES DA SILVA², ANA MARIA ALVES DE SOUZA RIBEIRO ${ }^{4}$
}

RESUMO - O objetivo do presente trabalho foi avaliar a qualidade pós-colheita de frutos de maracujáamarelo tratados com óleo de soja, nim e de copaíba e com vinho de jatobá, visando à redução da severidade da Antracnose, causada pelo fungo Colletotrichum gloeosporioides. Um experimento in vitro foi instalado no delineamento inteiramente casualizado, em esquema fatorial 4 x 5 , considerando os quatro referidos produtos em cinco concentrações: 0,$0 ; 0,5 ; 1,0 ; 1,5$ e $2,0 \mathrm{~mL} \mathrm{~L}^{-1}$, diluídos em meio BDA. Para o experimento in vivo, frutos de maracujá-amarelo foram desinfestados superficialmente com hipoclorito de sódio a $150 \mathrm{mg} \mathrm{L}^{-1} \mathrm{e}$ inoculados com uma suspensão de $10^{6}$ conídios $\mathrm{L}^{-1}$ de $C$.gloeosporioides. Após $24 \mathrm{~h}$, foram imersos por 10 min nos seguintes tratamentos: $0,5 \mathrm{~mL}^{-1}$ de vinho de jatobá; $0,25 \mathrm{~mL}^{-1}$ de óleo de copaíba; $0,5 \mathrm{~mL}^{-1}$ de óleo de soja; $0,5 \mathrm{~mL}^{-1}$ de óleo de nim e testemunha. Adotou-se o delineamento inteiramente casualizado. Análises de regressão foram usadas para os experimentos in vitro, sendo a severidade avaliada por escala diagramática e quantificação do número de lesões / fruto, e os tempos de vida útil dos frutos foram comparados pelo teste de Kruskal Wallis, a 5\% de probabilidade. A acidez total titulável (ATT), sólidos solúveis totais (SST), $\mathrm{pH}$, ácido ascórbico e a relação SST/ATT foram comparados pelo teste de Tukey, a 5\% de probabilidade. In vitro, o óleo de nim e de copaíba e o vinho de jatobá apresentaram comportamento quadrático, sendo as concentrações de 1,56;1,93 e 1,71 mL L $\mathrm{L}^{-1}$ as mais eficientes na redução do crescimento micelial do fungo, respectivamente. O óleo de soja reduziu o crescimento micelial do fungo linearmente ao aumento da sua concentração até o limite de $2 \mathrm{~mL} \mathrm{~L}^{-1}$. Os óleos de soja e nim promoveram maior redução da severidade da Antracnose avaliada pela escala diagramática. O segundo também reduziu o número de lesões / fruto, e o primeiro estendeu o tempo de vida útil dos frutos de maracujá por quatro dias. Os frutos tratados com óleo de soja e de copaíba apresentaram maior tempo de vida útil, teor de ATT e menor relação SST/ATT.

Termos para indexação: Passiflora edulis, Colletotrichum gloeosporioides, Controle alternativo.

\section{ANTHRACNOSE SEVERITY AND QUALITY OF YELLOW PASSION FRUITS TREATED WITH NATURAL PRODUCTS IN POST-HARVEST}

\begin{abstract}
The objective of present study was evaluate the quality of yellow passion fruits treated with oils of soybean, nim, copaiba and jatoba wine, aiming the reduction of severity of antracnosis caused by the fungi Colletotrichum gloeosporioides. An in vitro experiment was installed in a completely randomized design in a factorial scheme 4 X5 considering the four treatments in five concentrations: $0.0 ; 0.5 ; 1.0 ; 1.5$ and $2.0 \mathrm{~mL} \mathrm{~L}^{-1}$ diluted in PDA media. For the in vivo experiment, yellow passion fruits were surfaced sterilized with sodium hypochlorite at 150 $\mathrm{mg} \mathrm{L}^{-1}$ and inoculated with a suspension of $10^{6}$ conidia $\mathrm{L}^{-1}$ of $C$. gloeosporioides. After $24 \mathrm{~h}$ the treatments were immersed for $10 \mathrm{~min}$ at the following concentrations: $0.5 \mathrm{~mL}^{-1}$ of jatoba wine, $0.25 \mathrm{~mL}^{-1}$ of copaiba oil, $0.5 \mathrm{~mL}^{-1}$ of soybean oil, $0.5 \mathrm{~mL}^{-1}$ of nim oil and control. A completely randomized design was adopted. Regression analysis were used for the in vivo experiments, and the severity evaluated by diagrammatic scale and the quantification of number of injuries/fruit and the lifetimes of the fruits were compared by the test of Kruskal Wallis at $5 \%$ of probability. The titratable total acidity (TTA), soluble solid total (SST), pH, ascorbic acid, and SST/TTA ratio were compared by Tukey test at 5\% probability. In vitro the nim oil, copaiba oil and jatoba wine presented quadratic proceeding, being the concentrations of $1.56,1.93 \mathrm{e} 1.71 \mathrm{~mL} \mathrm{~L}^{-1}$ the most efficient in the reduction of fungi mycelial growth, respectively. The soybean oil reduced the fungi mycelial growth linearly with the increase of this concentration to the limit of $2 \mathrm{~mL} \mathrm{~L}^{-1}$. The oils of soybean and nim promoted more reduction of Anthracnose severity evaluated by diagrammatic scale. The nim oil also reduced the number of injuries / fruits and the soybean oil extended lifetime of passion fruits in four days. The fruits treated with soybean and copaiba oils presented more lifetime, TTA content and less SST/TTA ratio.
\end{abstract}

Index terms: Passiflora edulis, Colletotrichum gloeosporioides, Alternative control.

\footnotetext{
(Trabalho 082-11). Recebido: 21-02-2011. Aceito para publicação em: 01-11-2011.

${ }^{2}$ Engenheiro Agrônomo e Mestrando do PPG em Produção Vegetal da Universidade Federal do Acre. BR 364. Rio Branco- AC. CEP: 696115-900. e-mail: Jussiesolino@hotmail.com; Floydwatters@hotmail.com

${ }^{3}$ Professor Doutor do PPG em Produção Vegetal da Universidade Federa do Acre. Rio Branco- AC. BR 364, distrito industrial, CEP: 696115-900. e-mail: selviro2000@yahoo.com.br

${ }^{4}$ Graduanda de Agronomia da Universidade Federal do Acre. BR 364. Rio Branco- AC. CEP: 696115-900. e-mail: aninha_acre@hotmail.com
} 


\section{INTRODUÇÃO}

A fruticultura influencia atividades econômicas, sociais e alimentares, cujo consumo de produtos in natura e industrializados cresce rapidamente, gerando riquezas ao País, fixando o homem no campo e cumprindo papel expressivo na saúde humana. No entanto, existem grandes entraves na produção de frutas no Brasil, tais como o manejo inadequado da cultura, problemas na colheita, no armazenamento e transporte, além do ataque de pragas e doenças em pré e pós-colheita, com perdas que podem chegar a 40\%, dependendo da cultura (CHITARRA; CHITARRA, 2005; JUNQUEIRA et al., 2003).

O maracujá é um fruto conhecido principalmente por suas características exóticas e sensoriais, assim como também por seus aspectos nutricionais, seus teores de vitaminas, sais minerais e carboidratos (MELETTI, 2005). Entretanto, as perdas em póscolheita são expressivas, em função da alta vulnerabilidade dos frutos à perda de umidade e ao ataque de fungos, principalmente o Colletotrichum gloeosporioides, agente causal da Antracnose (FISCHER et al., 2005; COSTA; COSTA, 2005). Esta é uma das principais doenças que incidem em pós-colheita de várias frutas, incluindo o maracujá-amarelo (BENATO, 1999). A ocorrência da Antracnose é maior em regiões de alta umidade, no entanto se encontra disseminada por todo o Brasil, podendo causar grandes prejuízos ao produtor e limitar o crescimento da produção de maracujá (FISCHER et al., 2007).

Para o controle de patógenos, é essencial o uso de defensivos agrícolas com menor poder residual; entretanto, dificilmente isso é possível com a aplicação de produtos químicos em frutas após a colheita. No Brasil, há uma preocupação com a qualidade físico-química dos alimentos produzidos no campo, por isso a legislação brasileira, especificamente a de Produção Integrada de Frutas e de Produção Orgânica, rejeita e proíbe, respectivamente, o uso de agrotóxicos e incentiva métodos de controle agroecológicos em pós-colheita, visando a um sistema produtivo em conformidade com os requisitos da sustentabilidade ambiental, segurança alimentar e viabilidade econômica, de maneira que se disponha de técnicas menos agressivas ao meio ambiente e à saúde humana (BRASIL, 2001; SILVEIRA et al., 2005; BRASIL, 2003).

Os métodos de controle fitossanitários em pós-colheita devem ser adotados com vista à obtenção de frutos de melhor qualidade. Assim, a aplicação de produtos naturais com ação antibiótica ou antifúngica, como o óleo de soja, óleo de copaíba, óleo de nim, vinho de jatobá, entre outros, pode proporcionar um controle satisfatório de doenças pós-colheita.

O óleo de nim, o vinho de jatobá e o óleo de copaíba são largamente utilizados pelas comunidades tradicionais como antibióticos, cicatrizantes e no tratamento de doenças fúngicas em humanos (NEVES et al., 1993; NEVES et al., 2003; SOUZA et al., 2006; VEIGA JÚNIOR; PINTO, 2002). De modo que estas substâncias também podem exercer algum controle de doenças causadas por fungos em pós-colheita de frutos, como a Antracnose, que ocorre em frutos de maracujá. O uso de extratos e óleos de planta tem sido relatado com frequência no controle fitoterápico, in vitro e em planta (LAMEIRA, 2007; SCHWAN-ESTRADA et al., 2002; VENTUROSO, 2009; WANG et al., 2010), sugerindo que seu uso pode corresponder a estas expectativas.

A tendência da agricultura neste milênio é de produzir cada vez mais alimento, garantir a preservação do ambiente para as futuras gerações e a saúde alimentar dos consumidores. Assim, pesquisas com produtos naturais tornam-se imprescindíveis para atender a essa nova tendência, como tratamentos fitossanitários em pós-colheita.

Nesse contexto, o objetivo do trabalho foi avaliar a qualidade em pós-colheita dos frutos de maracujazeiro-amarelo (Passiflora edulis Sims. flavicarpa Deg.), tratados com óleos de soja, nim e de copaíba e com vinho de jatobá, visando à redução da severidade da Antracnose.

\section{MATERIAL E MÉTODOS}

Os experimentos in vitro e in vivo foram conduzidos na Unidade de Tecnologia de Alimentos (UTAL) e no Laboratório de Fitopatologia da Universidade Federal do Acre - UFAC, em Rio Branco-AC, Brasil, no período de novembro de 2008 a setembro de 2009.

Para isso, utilizaram-se frutos de maracujazeiro-amarelo provenientes do município de Presidente Médici-RO. Para o experimento in vitro, o fungo Colletotrichum gloeosporioides foi isolado de frutos de maracujazeiro-amarelo naturalmente infectados.

No experimento in vitro, foi usado o delineamento experimental inteiramente casualizado, em esquema fatorial $4 \times 5$, cujo primeiro fator é a aplicação dos produtos (óleos de soja; copaíba e nim, e vinho de jatobá), e o segundo fator, as concentrações $(0,0$; 0,$5 ; 1,0 ; 1,5$ e $\left.2,0 \mathrm{~mL} \mathrm{~L}^{-1}\right)$, totalizando 20 tratamentos com seis repetições de uma placa de Petri.

Discos de micélio de $0,4 \mathrm{~cm}$ de diâmetro provenientes de colônias puras foram transferidos para placas de Petri $(\varnothing=100 \mathrm{~mm})$ contendo meio de 
cultura batata-dextrose-ágar (BDA), $250 \mathrm{mg} \mathrm{L}^{-1}$ de Cloranfenicol e concentrações dos produtos naturais. Posteriormente, as placas foram mantidas em B.O.D., a $25^{\circ} \mathrm{C}$, com 12 horas luz e 12 horas sem luz.

A avaliação do crescimento micelial foi realizada aos 15 dias após a incubação das placas, medindo-se o diâmetro perpendicular das colônias. Posteriormente, os dados foram submetidos aos pressupostos de normalidade de resíduos de Shapiro-Wilk e homogeneidade de variância de Hartley, em seguida submetidos à análise de variância da regressão, a 5\% de probabilidade.

Os dados referentes aos óleo de copaíba e vinho de jatobá não atenderam aos pressupostos. Por isso, foram transformados por $\log \mathrm{x}$ e posteriormente submetidos à análise de variância da regressão, a 5\% de probabilidade, sendo os coeficientes submetidos ao teste de regressão.

Para o experimento in vivo, duas etapas foram realizadas: primeiramente foi realizada a determinação da concentração "ideal", correspondente à maior concentração do óleo de soja, nim e de copaíba e do vinho de jatobá, que não afetaram a aparência externa dos frutos tratados. Posteriormente, a severidade da antracnose foi avaliada por dois métodos, primeiro usando a escala diagramática de Fischer et al. (2009) e contando o número de lesões/fruto, além da avaliação de parâmetros químicos (acidez total titulável, ácido ascórbico, $\mathrm{pH}$, sólidos solúveis totais e relação sólidos solúveis totais/acidez total titulável) e vida útil dos frutos de maracujá-amarelo tratados com as concentrações ideais de cada produto, determinadas na primeira fase.

As concentrações avaliadas na primeira etapa foram: 4,$0 ; 3,0 ; 2,0 ; 1,0 ; 0,5 ; 0,4 ; 0,3 ; 0,25 ; 0,2$ e 0,1 $\mathrm{mL} \mathrm{L}^{-1}$ dos óleos de soja, nim e copaíba e do vinho de jatobá, com quatro repetições de um fruto cada.

No experimento in vivo, onde se empregou uso de óleos não emulsionáveis (soja e copaíba), utilizaram-se $150 \mathrm{~g} \mathrm{~L}^{-1}$ de nonilfenol como emulsionante.

Após o preparo das caldas, realizou-se a colheita de frutos sem defeitos e apresentando $65 \%$ das cascas amarelada. Segundo Silva et al. (2005), a partir desse estádio, os frutos de maracujá que se encontram amarelos, estão amadurecidos e possuem características físico-químicas excelentes para o consumo. Posteriormente, os mesmo foram lavados e desinfetados superficialmente com solução de hipoclorito de sódio a $150 \mathrm{mg} \mathrm{L}^{-1}$, enxaguados com água esterilizada e deixados à temperatura ambiente de laboratório para secarem. Posteriormente, os frutos foram imersos por 10 minutos nas respectivas soluções e, depois, mantidos em condição ambiente de laboratório, para a avaliação das características indesejáveis relacionadas à oleosidade, viscosidade, desidratação e manchas de queima dos frutos. Assim, foram descartados tratamentos que apresentavam alguma das características acima descritas.

A concentração ideal do óleo de copaíba foi de $0,25 \mathrm{~mL} \mathrm{~L}^{-1}$, pois concentrações maiores proporcionam elevação na viscosidade dos frutos, característica indesejável na comercialização. Da mesma forma, a concentração ideal do óleo de soja foi de $0,5 \mathrm{~mL} \mathrm{~L}^{-1}$, pois acima desta, os frutos passaram a exibir maior oleosidade. Para o óleo de nim e o vinho de jatobá, a concentração ideal foi de $0,5 \mathrm{~mL} \mathrm{~L}^{-1}$, pois as superiores a esta promoveram maior desidratação dos frutos.

Após os testes preliminares, passou-se à implantação da segunda etapa do experimento in vivo. Assim, os frutos foram colhidos, lavados e desinfetados superficialmente com solução de hipoclorito de sódio a $150 \mathrm{mg} \mathrm{L}^{-1}$, enxaguados com água esterilizada e deixados à temperatura ambiente de laboratório para secarem. Posteriormente os frutos foram aspergidos com uma suspensão de $10^{6}$ espo$\operatorname{ros} \mathrm{L}^{-1}$. A concentração da suspensão de esporos foi predeterminada com o auxílio de uma câmara de Newbauer, conforme Dutra (2008).

Realizadas as inoculações, os frutos foram acondicionados em bandejas plásticas a $25{ }^{\circ} \mathrm{C}$ e $80-90 \%$ de UR. A aplicação dos tratamentos foi realizada 24 horas após a inoculação do patógeno, imergindo-se os frutos durante 10 minutos nas respectivas concentrações dos produtos, adaptados de Junqueira et al. (2004) e retornados à condição de controle de temperatura e UR.

Os tratamentos foram constituídos dos produtos naturais e respectivas concentrações, dispostos no delineamento experimental inteiramente casualizado, com 10 repetições de um fruto cada. Os tratamentos foram assim construídos: T1. Testemunha; T2. $0,5 \mathrm{ml} \mathrm{L}^{-1}$ de vinho de jatobá; T3. $0,25 \mathrm{ml} \mathrm{L}^{-1}$ de óleo de copaíba; T4. 0,5 $\mathrm{ml} \mathrm{L}^{-1}$ de óleo de soja; T5. $0,5 \mathrm{ml} \mathrm{L}^{-1}$ de óleo de nim.

As variáveis analisadas foram: severidade da antracnose, características bioquímicas e tempo de vida útil dos frutos. A severidade foi avaliada com o uso da escala diagramática descrita por Fischer et al. (2009), atribuindo-se notas em porcentagem com variações de 1 a $70 \%$, e através da quantificação do número de lesões ou manchas por fruto.

A avaliação da severidade de antracnose, por ambos os métodos, foi realizada quando os frutos atingiram $8 \%$ de perda de massa, conforme recomendações da Federação do Estado do Paraná - FAEP (2008), que considera murcho o fruto que exibe aparência prejudicada, tendo seu valor 
comercial depreciado. Assim, a vida útil dos frutos foi determinada pelo tempo, em dias, que o fruto levou para atingir $8 \%$ de perda de massa.

Para as análises bioquímicas, como acidez total (ATT), teor de sólidos solúveis totais (SST), relação SST/ATT, ácido ascórbico e pH, o suco foi extraído por prensagem manual da polpa dos frutos e posterior filtragem em tela de náilon.

$\mathrm{O}$ teor de SST, expresso em ${ }^{\circ} \mathrm{BRIX}$, foi determinado por meio da leitura direta em refratômetro óptico à temperatura ambiente de $20{ }^{\circ} \mathrm{C}$ e leitura na faixa de 0 a $32 \%$. A ATT, determinada pela titulação da amostra com hidróxido de sódio $(\mathrm{NaOH}, 0,1 \mathrm{~N})$, foi expressa em porcentagem de ácido cítrico (A.O.A.C, 1990). O pH foi determinado diretamente em $40 \mathrm{~mL}$ de amostra homogeneizada, utilizando-se de potenciômetro (pH-metro) digital, previamente calibrado com solução tampão de $\mathrm{pH}$ 4,0 e 7,0, segundo as normas analíticas da A.O.A.C. (1990). O teor de ácido ascórbico foi determinado segundo os procedimentos do Instituto Adolfo Lutz (2005) e expresso em MG de ácido ascórbico por $100 \mathrm{~g}$ de suco.

Os dados obtidos de todas as variáveis foram submetidos ao teste de Shapiro Wilk, a 5\% de probabilidade, para a verificação das normalidades dos resíduos, e de Hartley, a 5\% de probabilidade, para a verificação da homogeneidade de variância.

Os dados relativos ao tempo de vida útil dos frutos e severidade da Antracnose, em percentagem e número de lesões/frutos, não atenderam aos pressupostos de normalidade dos resíduos e de homogeneidade das variâncias, sendo necessário analisá-los pelo teste não paramétrico de KruskalWalls. Já os dados das variáveis ATT, relação SST/ ATT e o teor de ácido ascórbico não atenderam à normalidade de resíduos, pelo teste de Shapiro Wilk, a $5 \%$ de probabilidade. Por isso, foram transformados pelo Log (x-0,2), Ln ( $\mathrm{x}+1)$ e Raiz $(\mathrm{x}-0,39)$, respectivamente. Posteriormente, os dados foram submetidos à análise da variância, sendo as médias dos tratamento comparadas pelo teste de Tukey, a $5 \%$ de probabilidade, para a identificação do tratamento mais eficiente no controle da Antracnose e na manutenção das qualidades pós-colheita dos frutos.

A análise de correlação simples, ao nível de $5 \%$ de probabilidade, foi realizada entre a severidade da Antracnose, em percentagem e número de lesões/ fruto, e o tempo de vida útil do maracujá-amarelo.

\section{RESULTADOS E DISCUSSÃO}

Nas análises dos experimentos in vitro, observou-se redução significativa do crescimen- to micelial do fungo C. gloeosporioides, sendo a regressão quadrática a que melhor representou o comportamento dos dados para os tratamentos com óleo de copaíba e nim $(\mathrm{P}<5 \%)$, e com vinho de jatobá $(\mathrm{P}<1 \%)$, obtendo-se redução máxima a 1,$56 ; 1,93 \mathrm{e}$ $1,71 \mathrm{~mL} \mathrm{~L}^{-1}$, respectivamente. Já com o óleo de soja, esse comportamento seguiu uma regressão linear $(\mathrm{P}<5 \%)$ (Figura 1).

Há vários relatos a respeito do uso do óleo de nim, copaíba e soja e de extratos de jatobá no controle de fungos, explicando que sua eficácia depende da concentração aplicada, mas, sobretudo, é dependente da espécie fúngica alvo (AMORIM et al., 2004; OGBEBOR et al., 2007; OLIVEIRA et al., 2006; SOUZA; SOARES, 2009). O óleo de nim não inibiu efetivamente o crescimento micelial de C. gloeosporioides, mas atingiu redução máxima de $42,9 \%$ a 1,56 $\mathrm{mL} \mathrm{L}^{-1}$. Essa ação fungistática deve-se à presença de substâncias bioativas, principalmente da azadiractina (DIAS-AIEIRA et al., 2010; MEDICE et al., 2007).

O óleo de copaíba reduziu em $24,4 \%$ o diâmetro do crescimento micelial até a concentração de $1,93 \mathrm{~mL} \mathrm{~L}^{-1}$ em relação ao tratamento-controle. Há descrição da eficácia do óleo de copaíba no controle de diversas espécies fúngicas, como Aspergillus flavus, A. niger, A. tamarii, A. terreus, Candida guilliermandii, C. tropicallis, C. parapsilosis, Bipolares sorokiniana e C. gloeosporioide. Contudo, houve grande variação na porcentagem de inibição do crescimento da colônia, em função da maior ou menor resistência de algumas espécies às substâncias tóxicas presentes no óleo (AMORIM et al., 2004; DEUS et al., 2009; OLIVEIRA et al., 2006). O efeito fungistático do óleo de copaíba pode estar relacionado à presença de diterpenos e sequisterpenos, cuja principal substância responsável pela inibição de fungos é o $\beta$-cariofileno e seus óxidos derivados (MACIEL, et al., 2002; VEIGA JÚNIOR; PINTO, 2002; VEIGA JÚNIOR et al.,1997).

O vinho de jatobá atingiu inibição máxima de $19,82 \%$ do diâmetro do crescimento micelial do C. gloeosporioides na concentração de $1,71 \mathrm{~mL} \mathrm{~L}^{-1}$. Souza et al. (2009) também observaram esse efeito fungistático sobre Sclerotium rolfsii, Fusarium oxysporum e Rhizoctonia solani, reduzindo o diâmetro do crescimento micelial em até $90 \%, 30 \%$ e $80 \%$, respectivamente. O jatobá possui componentes químicos, como os taninos e flavonoides, cujos compostos estão associados à ação antifúngica (FERNANDES et al., 2005).

O óleo de soja reduziu o crescimento micelial do fungo de forma linear e proporcional ao aumento da sua concentração, atingindo $12 \%$ de redução do diâmetro da colônia de C. gloeosporioides a $2 \mathrm{~mL} \mathrm{~L}^{-1}$ 
(Figura 1). Junqueira et al. (2004) verificaram que a aplicação de $100 \mathrm{~mL} \mathrm{~L}^{-1}$ e $200 \mathrm{~mL} \mathrm{~L}^{-1}$ de óleo de soja reduziu $26 \%$ e $53 \%$ a incidência e a severidade da Antracnose em mangas, respectivamente, quando comparada ao tratamento de $50 \mathrm{~mL} \mathrm{~L}^{-1}$, constatando sua eficácia no controle da Antracnose.

Verificou-se significância de $1 \%$ de probabilidade, pelo teste de Kruskal-Walls, para a variável severidade. O óleo de nim promoveu a maior redução da severidade da Antracnose, quando avaliada tanto pela escala diagramática de FISCHER et al. (2009) como pela quantificação do número de lesões/fruto, atingindo 72,7 e $43,7 \%$, respectivamente, seguido do óleo de soja com 71,2 e $36,6 \%$, em relação ao tratamento-controle, respectivamente (TABELA 1). O efeito fungistático ou inibitório do óleo de nim, provavelmente se deve à presença de substâncias bioativas com alto poder biológico, como a azadiractina (DIAS-AIEIRA et al. 2010; MEDICE et al., 2007).

A eficácia do óleo de soja na redução da severidade da Antracnose também foi constatada em pesquisas com manga e em banana, proporcionando inibição total ou parcial da severidade da doença em frutos (JUNQUEIRA et al., 2003; JUNQUEIRA et al., 2004). O óleo de soja é rico em ácidos graxos, principalmente ácido linoléico, que possui conhecida ação fungistática (SILVA, 1999; SILVA et al., 2001).

A aplicação do vinho de jatobá promoveu acréscimo na severidade da Antracnose. Esse aumento ocorreu em função da suscetibilidade imposta aos frutos ao se aplicar o vinho, visto que, na determinação das concentrações, os frutos apresentavam aspecto murcho, em consequência da perda de massa fresca, o que acelera o processo de senescência e aumenta o pico respiratório. Chitarra e Chitarra (2005) relataram que, na pós-colheita de frutas, a respiração é o principal processo fisiológico, de maneira que a intensidade das reações determina a menor ou maior produção de etileno, que, por conseguinte, tornam os frutos suscetíveis aos patógenos ou, até mesmo, a oportunistas e saprófitos.

Pela análise de correlação simples entre os dados de severidade da Antracnose, avaliada pela escala diagramática e pelo número de lesões/fruto, verificou-se correlação positiva $\left(\mathrm{r}=0,68^{*}\right)$, ratificando que o aumento do número de lesões/fruto agrava a severidade da doença. Assim, tornou-se evidente a necessidade do uso de produtos que atuem na inibição da germinção dos esporos e/ou no estabelecimento das relações patógenos-hospedeiro ou infecção propriamente dita.

A redução da severidade da Antracnose obtida com a aplicação dos óleos de soja, nim e de copaíba deveu-se à presença de substâncias tóxicas ao fungo, o que foi evidenciado no experimento in vitro. No entanto, no experimento in vivo, observou-se maior redução da ação do fungo, fator que pode estar ligado às condições desfavoráveis ao estabelecimento das relações patógeno-hospedeiro.

Verificou-se significância de $1 \%$ de probabilidade pelo teste de Kruskal-Walls para a variável vida útil, de modo que a aplicação do óleo de copaíba estendeu o tempo de vida útil dos frutos em relação aos demais tratamentos, retardando a perda de massa durante 12 dias, quatro dias a mais que o tratamentocontrole (Figura 2). Estes frutos apresentaram aspecto mais túrgido e com melhores condições de comercialização. Segundo a Federação do Estado do Paraná - FAEP (2008), o maracujá-amarelo é considerado murcho ao atingir $8 \%$ de perda de massa, pois prejudica a aparência do fruto, depreciando seu valor comercial.

O maior tempo de conservação do maracujáamarelo foi atingido com a aplicação do óleo de copaíba, seguido do óleo de soja, podendo estar associado à formação de uma película de proteção no epicarpo do fruto, que retarda a perda de água e reduz as trocas gasosas. Com isso, há uma redução do metabolismo do fruto, pois as alterações químicas nos frutos ocorrem em baixos níveis de oxigênio (CHITARRA; CHITARRA, 2005; JUNQUEIRA et al. 2004; PEREIRA; BELTRAN, 2002). Entretanto, a longevidade dos frutos também envolve outros fatores, mas, principalmente, o acometimento de doenças.

Bettiol (2005) relata que, ao modificar a atmosfera, principalmente com revestimentos que reduzam a concentração de $\mathrm{O}_{2}$ e/ou aumentem a de $\mathrm{CO}_{2}$, em condições de armazenamento, pode-se inibir o desenvolvimento de patógenos, diretamente, por meio da supressão do crescimento e ou, indiretamente, por meio da manutenção da resistência do hospedeiro, retardando, com isso, os processos de maturação e senescência. Isso foi evidenciado, quando se observou maior inibição in vivo que in vitro, usando-se óleo de copaíba e de soja, além da ação fungistática devida às propriedades químicas do próprio produto. Ademais, foi observado que o vinho de jatobá acelerou o processo respiratório, enquanto os óleos de copaíba e soja apresentaram ação contrária.

A correlação simples entre os dados de severidade da Antracnose, avaliada pela escala diagramática e pelo número de lesões/fruto, e o tempo de vida útil dos frutos, apontou para uma correlação negativa, $r=-0,31(\mathrm{P}<1 \%)$ e $-0,46(\mathrm{P}<1 \%)$, respectivamente. Assim, o aumento da severidade observada com o uso do vinho de jatobá, ou a re- 
dução da severidade observada com o uso do óleo de soja e de nim, pode explicar que o tempo de vida útil dos frutos pode ser estendido com a redução da severidade da doença, e vice-versa.

A variável ATT foi maior em frutos tratados com óleo de soja e de copaíba e menor no tratamento com vinho de jatobá (Tabela 2). Provavelmente, esse aumento foi devido à redução do metabolismo promovido pela película formada pelos óleos, que, por sua vez, reduzem o oxigênio nos espaços intracelulares dos frutos e diminuem, consequentemente, a respiração. A respiração tem como função suprir energia química aos tecidos, na forma de trifosfato de adenosina (ATP), seguindo vias bioquímicas que utilizam largamente os ácidos orgânicos como substrato (CHITARRA; CHITARRA, 2005).

Os teores de SST e de ácido ascórbico não diferiram estatisticamente em frutos tratados com óleo de soja, nim e de copaíba e com vinho de jatobá, em relação aos frutos do tratamento-controle (Tabela 2). Os resultados obtidos no presente trabalho, especificamente de SST, ficaram abaixo dos valores observados por outros pesquisadores (MACHADO et al., 2003; MARCHI et al., 2000; SILVA, 2002). Já o ácido ascórbico pode ser utilizado como um índice de qualidade dos alimentos, pois varia nos frutos de acordo com as condições de armazenamento (CHITARRA; CHITARRA, 2005). Contudo, não se verificam exigências relacionadas ao mesmo no caso de frutas destinadas à industrialização (MARCHI et al., 2000).

$\mathrm{O}$ pH do suco de maracujá-amarelo não apresentou diferença estatística entre os tratamentos. Porém, uma correlação positiva foi observada entre $\mathrm{pH}$ e ATT dos frutos. No entanto, muitos ácidos podem estar associados com sais de potássio, constituindo sistemas tampões que permitem grandes variações na ATT sem influenciar significativamente sobre o pH (CHITARRA; CHITARRA, 2005).

A relação SST/ATT foi menor em frutos tratados com óleo de soja e de copaíba, em comparação aos frutos dos demais tratamentos (Tabela 2). Gamarra-Rojas e Medina (1996) afirmam que essa relação pode variar em função da diminuição da acidez ao longo do armazenamento. Com visto na Tabela 2, os frutos tratados com óleo de soja apresentaram maior teor de acidez, o que implicou menor quociente da relação SST/ATT. Essa relação é muito utilizada na determinação do "flavor" dos frutos, pois quanto maior o valor, melhor será a qualidade do fruto e melhor será sua aceitação no mercado (CHITARRA; CHITARRA, 2005). Entretanto, o consumo do maracujá in natura tem sido realizado por meio do preparo de sucos e sobremesas, em que a acidez é apreciada, ou na indústria, que não considera esses valores, como ocorre com os demais frutos tropicais. Contudo, os valores observados no presente trabalho estão de acordo com os obtidos por Silva (2002).

TABELA 1 - Médias da porcentagem da área lesionada/fruto e do número de lesões/fruto causadas por Colletotrichum gloeosporioides em frutos de maracujá-amarelo tratados com óleo de soja, copaíba e de nim e com vinho de jatobá, ao atingirem $8 \%$ de perda de massa, Rio Branco-AC, UFAC, 2010

\begin{tabular}{lcc}
\hline Tratamentos & Área lesionada/fruto (\%) & Número de lesões/fruto \\
\hline Óleo de Soja & $11,50 \mathrm{a}$ & $7,10 \mathrm{~b}$ \\
Óleo de Nim & $10,90 \mathrm{a}$ & $6,30 \mathrm{a}$ \\
Vinho de Jatobá & $52,10 \mathrm{~d}$ & $11,40 \mathrm{~d}$ \\
Óleo de Copaíba & $25,30 \mathrm{~b}$ & $7,60 \mathrm{c}$ \\
Controle & $40,00 \mathrm{c}$ & $11,20 \mathrm{~d}$ \\
\hline
\end{tabular}

Médias seguidas pela mesma letra na coluna não diferem entre si, a 5\% de probabilidade, pelo teste de Kruskal-Walls. 


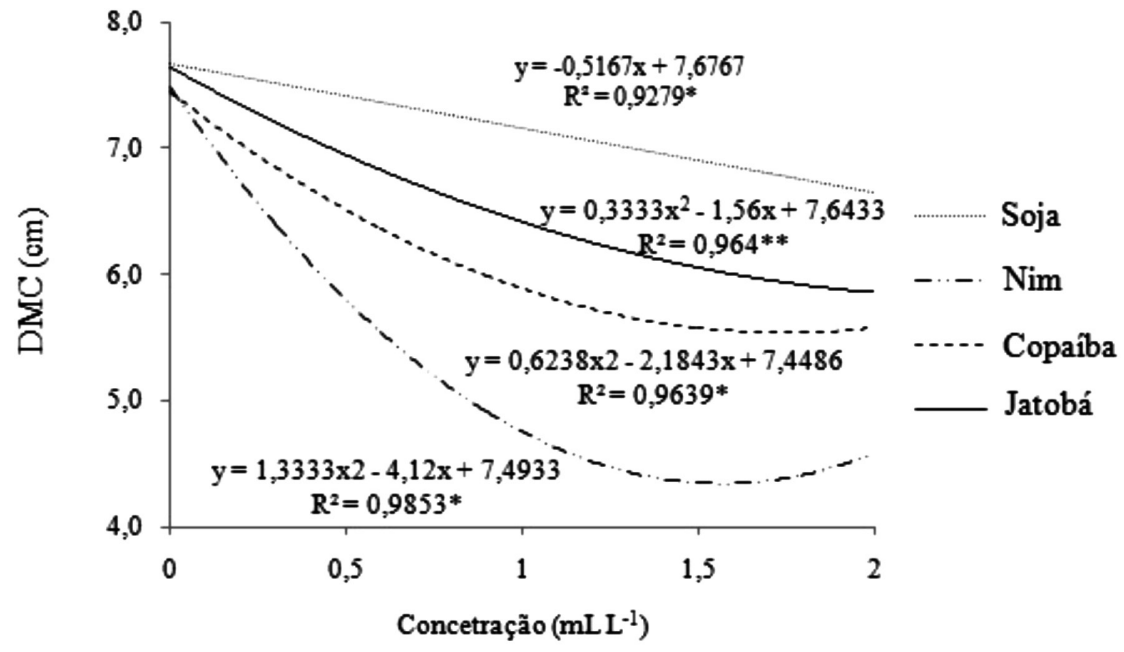

FIGURA 1 - Diâmetro médio do crescimento micelial (DCM) do fungo Colletotrichum gloeosporioides em função da concentração dos óleos de soja, nim e de copaíba e do vinho de jatobá diluídos em BDA, aos 15 dias. Rio Branco-AC, UFAC, 2010.

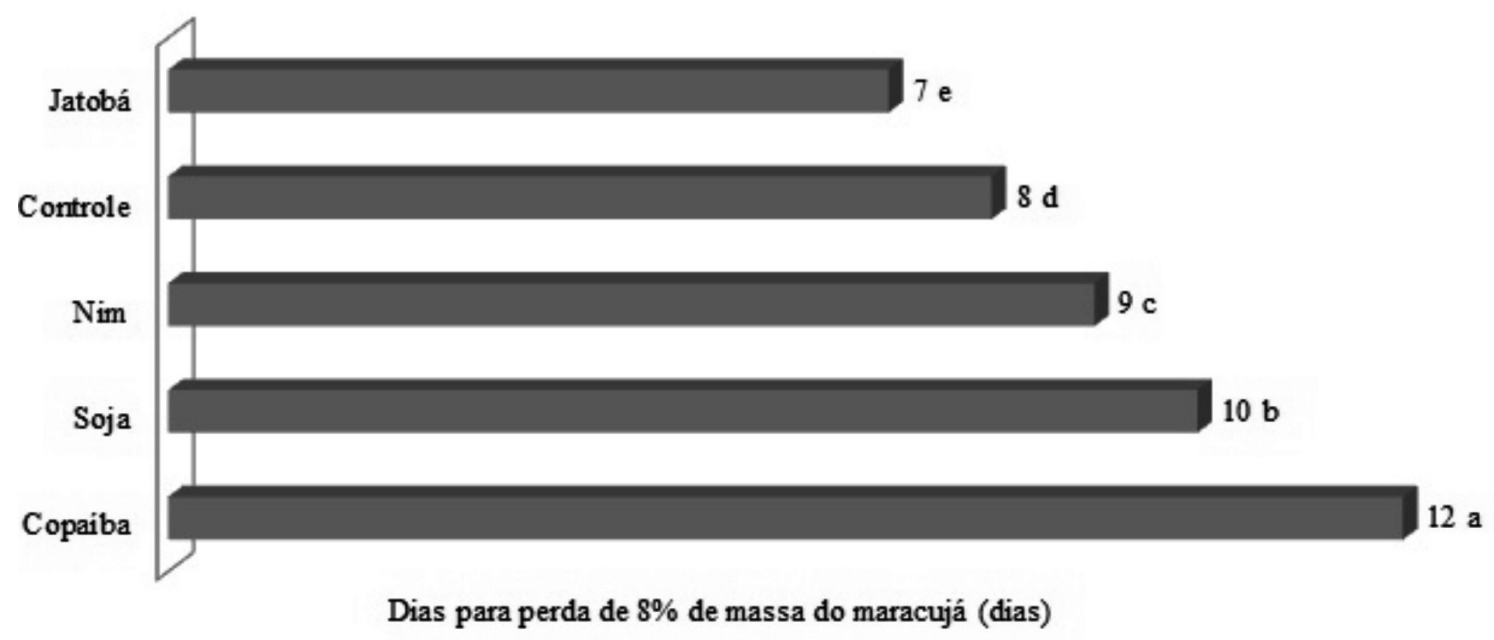

FIGURA 2 - Tempo de vida útil (dias) de frutos de maracujá-amarelo tratados com óleo de soja, copaíba, e de nim e com vinho de jatobá, ao atingirem $8 \%$ de perda de massa. Médias seguidas pela mesma letra não diferem entre si, a 5\% de probabilidade, pelo teste de Kruskal-Walls, Rio Branco-AC, UFAC, 2010. 
TABELA 2 - Médias da acidez total titulável (ATT), sólidos solúveis totais (SST), ácido ascórbico, pH e da relação SST/ATT em frutos de maracujá-amarelo submetidos a imersão em produtos naturais em pós-colheita, ao atingirem 8\% de perda massa. Rio Branco-AC, UFAC, 2010.

\begin{tabular}{lccccc}
\hline Tratamentos & $\begin{array}{c}\text { Acidez Total Titulável } \\
(\% \text { AC. Cítrico })\end{array}$ & $\begin{array}{c}\text { Sólidos solúveis }^{1} \\
\left({ }^{\circ} \text { BRIX }\right)\end{array}$ & $\begin{array}{c}\text { Ácido ascórbico }^{1} \\
\left(\mathrm{mg}^{\circ} 100 \mathrm{~g}^{-1}\right)\end{array}$ & $\mathrm{pH}$ & SST/ATT $^{1}$ \\
\hline Óleo de Soja & $5,39 \mathrm{a}$ & $12,31 \mathrm{a}$ & $40,16 \mathrm{a}$ & $2,89 \mathrm{a}$ & $2,30 \mathrm{~b}$ \\
Óleo de Nim & $4,25 \mathrm{bc}$ & $13,05 \mathrm{a}$ & $39,13 \mathrm{a}$ & $2,88 \mathrm{a}$ & $3,0 \mathrm{a}$ \\
Vinho de Jatobá & $4,18 \mathrm{c}$ & $12,97 \mathrm{a}$ & $39,27 \mathrm{a}$ & $2,85 \mathrm{a}$ & $3,14 \mathrm{a}$ \\
Óleo de Copaíba & $4,88 \mathrm{ab}$ & $12,89 \mathrm{a}$ & $44,91 \mathrm{a}$ & $2,85 \mathrm{a}$ & $2,67 \mathrm{~b}$ \\
Controle & $4,24 \mathrm{bc}$ & $13,58 \mathrm{a}$ & $36,10 \mathrm{a}$ & $2,85 \mathrm{a}$ & $3,12 \mathrm{a}$ \\
\hline CV\% & 8,05 & 6,65 & 7,28 & 1,59 & 6,25 \\
\hline
\end{tabular}

Médias seguidas pela mesma letra na coluna não diferem entre si, a 5\% de probabilidade, pelo teste de Tukey.

\section{CONCLUSÕES}

1-O óleo de soja, nim e de copaíba e o vinho de jatobá apresentam atividade fungistática sobre Colletotrichum gloeosporioides do maracujazeiro, em ensaio in vitro.

2-O óleo de soja e de nim proporcionam maior redução da severidade da Antracnose em frutos de maracujá-amarelo.

3-O vinho de jatobá aumenta a severidade da Antracnose e reduz o tempo de vida útil de frutos de maracujá-amarelo.

\section{REFERÊNCIAS}

AMORIM, A. C. L.; CARDOSO, M. das G.; PINTO, J. E. B. P.; SOUZA, P. E. de; DELÚ FILHO, N. Fungitoxic activity avaliation of the hexane ande metanol extratcts of copaíba plant leanes Capaifera langsforffi Desfon. Ciência e Agrotecnologia, Lavras, v. 28, n.2, p. 314-322, 2004.

AOAC - ASSOCIATION OF OFFICALANALITICAL CHEMISTS. Official methods of analysis of the Association of Official Analitical Chemists. 15. ed. Washington, 1990. v.2.

BENATO, E. Controle de doenças pós-colheita em frutas tropicais. Summa Phytopatologica, Jaboticabal, v. 25, n.1, p.90-93, 1999.

BETTIOL, W.; GHINI, R. Controle físico. In: BERGAMIM FILHO, A.; KIMATI. H.; AMORIM, L. Manual de fitopatologia. 3. ed. São Paulo: Ceres, 2005. p. 786-803.
BRASIL. Ministério da Agricultura, Pecuária e Abastecimento. Instrução Normativa ${ }^{\circ} \mathbf{2 0}$, de 27 de setembro de 2001. Disponivel em: <www.agricultura. gov.br>. Acesso em: 29 jun. 2009.

BRASIL. Ministério da Agricultura. Lei n ${ }^{\circ} 10.831$, de 23 de dezembro de 2003. Dispõe sobre a agricultura orgânica. Disponível em: <www.agricultura.gov. br>. Acesso em: 09 out. 2009.

CHITARRA, M. I. F.; CHITARRA, A. B. Pós-colheita de frutas e hortaliças: fisiologia e manuseio. 2. ed. rev. amp. Lavras: Universidade Federal de Lavras, 2005.

CIA, P. Doenças de pós-colheita em frutos (Caqui, Maracujá-doce e Nêspera). Botucatu: Instituto de Tecnologia de Alimentos; Centro de Tecnologia de Hortifrutícolas, 2002.

COSTA, A. de F. S. da; COSTA, A. N. da. Tecnologias para produção de maracujá. Vitória: INCAPER, 2005.

DEUS, R. J.A.; CARVALHO, A. S. C.; BANNA, D. A. D. S.; ARRUDA, M. S. P.; ALVES, C. N.; SANTOS, A. S. Efeito fungitóxico in vitro do óleo resina e do óleo essencial de copaíba (Copaifera multijuga Hayne). Revista Brasileira de Plantas Medicinais, Botucatu, v. 11, n. 3, p. 347-353, maio 2009.

DIAS-ARIEIRA, C. R.; FERREIRA, L. da R.; ARIEIRA, J. de O.; MIGUEL, E. G.; DONEGO, M. A.; RIBEIRO, R. C. F. Atividade do óleo de Eucalytus citriodora e Azadirachta indica no controle de Colletotrichum acutatum em morangueiro. Summa Phytopathologyca, Botucatu, v. 36, n. 3, p. 223-232, set. 2010. 
DUTRA, J. B. Controle da Antracnose (Colletotrichum gloeosporioides) pós-colheita do maracujá-amarelo (Passiflora edulis f. flavicarpa) por aplicações de fosfitos, água quente e 1-metilciclopropeno. 2008. 151 f. Dissertação (Mestrado em Fitopatologia) -Universidade de Brasília, Brasília, 2008.

FAEP - Federação da Agricultura do Estado do Paraná. Classificação do maracujá-amarelo. Disponível em: <http://www.faep.com.br/comissoes/ frutas/cartilhas/frutas/maracuja.htm>. Acesso em: ago. 2009.

FERNANDES, T. T.; SANTOS, A. T. F. dos; PIMENTA, F. C. Atividade antimicrobiana das plantas Phathymenia reticulada, Hymenaea courbaril e Guazuma ulmifolia. Patologia Tropical, Goiânia, v. 39, n. 2, p. 113-122, 2005.

FISCHER, I. H.;ALVES, S. A. M.; ALMEIDA, A. M. de; ARRUDA, M. C. de; ALMEIDA, A. M. de; BERTANI, R. N.; GARCIA, M. J. de M. Elaboração e validação de escala diagramática para a quantificação da severidade da Antracnose em frutos de maracujáamarelo. Summa Phytopathologica, Botucatu, v. 35, n. 3, p. 226-228, 2009.

FISCHER, I. H.; ARRUDA, M. C. de; ALMEIDA, A. M. de; GARCIA, M. J. de M.; JERONIMO, E. M.; PINOTI, R. N.; BERTANI, R. N. de A. Doenças e características físicas e químicas pós-colheita em maracujá-amarelo de cultivo convencional e orgânico no centro-oeste paulista. Revista Brasileira de Fruticultura, Jabuticabal, v. 29, n. 2, p. 254-259, 2007.

FISCHER, I. H.; KIMATI, H.; REZENDE, J. A. M. Doenças do maracujazeiro: (Passiflora spp.). In: KIMATI, H.; AMORIM, L.; REZENDE, J. A. M.; BERGAMIM FILHO, A.; CAMARGO, L. E. A. Manual de fitopatologia: doenças das plantas cultivadas. 4. ed., São Paulo: Agronômica Ceres, 2005. v.2.

GAMARRA-ROJAS, G.; MEDINA, V. M. Mudanças bioquímicas do suco do maracujá-amarelo em função da idade do fruto. Revista Brasileira de Fruticultura, Jaboticabal, v.18, n.1, p. 75-83, 1996.

INSTITUTO ADOLFO LUTZ. Métodos físicoquímicos para análise de alimentos. 2005. Disponível em: $<$ http://www.ial.sp.gov.br/index. php?option $=$ com_Remository \&Itemid $=0 \&$ func $=$ S elect\&orderby $=1>$. Acesso em: 18 nov. 2009.
JUNQUEIRA, N. T. V.; ANSELMO, R. M.; PINTO, A. C. Q.; RAMOS, V. H. V.; PEREIRA, A. V.; NASCIMENTO, A. C. Severidade da Antracnose e perda de matéria fresca de frutos de dez procedências de maracujazeiro-doce (Passiflora alata Dryander) em dois ambientes de armazenamento. Revista Brasileira de Fruticultura, Jaboticabal, v. 25, n. 1, p. 71-73, abr. 2003.

JUNQUEIRA, N. T. V.; CHAVES, R.da C.; NASCIMENTO, A. C. do; RAMOS, V. H. V.; PEIXOTO, J. R.; JUNQUEIRA, L. P. Efeito do óleo de soja no controle da Antracnose e na conservação da manga Cv. Palmer em pós-colheita. Revista Brasileira de Fruticultura, Jaboticabal, v. 26, n.2. p. 222-225, 2004.

LAMEIRA, C. N. Atividade do óleo-resina de copaifera reticulata Ducke no crescimento micelial in vitro de fitoptógenos. 2007. 36 f. Dissertação (Mestrado em Agronomia - Área de Concentração Produção Vegetal) - Universidade Federal Rural da Amazônia, Belém, 2007.

MACIEL, M. A. M.; PINTO, A. C.; VEIGA JÚNIOR, V. F. Plantas medicinais: a necessidade de estudos multidisciplinares. Química Nova, São Paulo, vol.25, n.3, p. 429-438. 2002.

MACHADO, S. S.; CARDOSO, R. L.; MATSUURA, F. C. A. U.; FOLEGATTI, M. I. S. Caracterização física e físico-química de frutos de maracujá-amarelo provenientes da região de Jaguaquara - Bahia. Magistra, Cruz das Almas, v. 15, n. 2, 2003.

MARCHI, R. de; MONTEIRO, M.; BENATO, E. A.; SILVA, A. R. da. USO DA COR DA CASCA COMO INDICADOR DE QUALIDADE DO MARACUJÁAMARELO (Passiflora edulis Sims. f. flavicarpa Deg.)DESTINADO À INDUSTRIALIZAÇÃO. Ciência e Tecnologia de Alimentos, Campinas, v. 20 n. 3, 2000.

MEDICE, R.; ALVES, E.; ASSIS, R. T. de; MAGNO JÚNIOR, R. G.; LOPES, E. A. das G. L. Óleos essenciais no controle da ferrugem asiática da soja Phakospsora pachyrhizi Syd. E P. Syd. Ciência e Agrotecnologia, Lavras, v. 31, n. 1, p. 83-90, 2007.

MELETTI, L. M. M. Maracujá-roxo. Revista Brasileira de Fruticultura, Jaboticabal, v. 27, n. 2. p.194-348, 2005.

NEVES, B. P. das; OLIVEIRA, I. P. de; MOHN, J. C. Cultivo e utilização do nim indiano. Santo Antônio de Goias: Embrapa Arroz e Feijão, 2003 (Circular Técnica, 62) 
NEVES, M. C. A.; NEVES, P. C. A.; ZANINI, J. C.; MEDEIROS, Y. S.; YUNES. R.A. CALIXTO, J. RB. Analgesic and antiiflamatory activities of the crede hydroalcohalic extract obtained from the bark of Hymenaea martiana. Phytotherapy Research, v. 7, p. 356-362, 1993.

OGBBOR, N. O.; ADEKUNLE, A. T.; ANOBAKHARE, D. A. Inhibition of Colletotrichum gloeosporioides (PENS) Sacc. Causal organism of Rubber (Hevea brasiliensis Mueel. Arg.) leaf spot using plant extract's. African Journal of Biotechnology, Nairobi, v. 6, n. 3, p. 213-218, 2007.

OLIVEIRA, E. C. P.; LAMEIRA, O. A.; BARROS, P. L. C. de; POLTRONIERI, L. S. Avaliação do óleo de copaíba (Copaifera spp) na inibição do crescimento micelial in vitro de fitopatógenos. Ciências Agrárias, Belém, n. 46, p. 53-63, 2006.

PEREIRA, W. S. P.; BELTRAN, A. Mecanismo de ação e uso do 1-MCP, bloqueador da ação do etileno visando a prolongar a vida útil das frutas. In: ZAMBOLIM, L. (Org.). Manejo integrado: fruteiras tropicais: doenças e pragas, Viçosa: UFV, 2002.

SCHWAN-ESTRADA, K. R. F.; STANGARLIN, J. R.; CRUS, M. E. da S. Uso de extratos vegetais no controle de fungos fitopatogênicos. Floresta, Maringá, v. 30, n. 2, p. 129-137, 2002.

SILVA, M.D. Avaliação bioquímica da Via das Lipoxigenases em plantas de soja infectadas com cancro da haste. 1999. 43 f. Dissertação (Mestrado em Agroquímica) - Universidade Federal de Viçosa, Viçosa, 1999.

SILVA, A. A. G. da. Maracujá-amarelo (Passiflora edulis Sims f. flavicarpa Deg.). 2002. 98 f. Tese (Doutorado em Agronomia - Área de Concentração Irrigação e Drenagem) - Faculdade de Ciências Agronômicas, Universidade Estadual Paulista, Botucatu, 2002.

SILVA, M. D. da; OLIVEIRA, M. G. de A.; LANNA, A. C.; PIRES, C. V.; PIOVESAN, N. D.; JOSÉ, I. C.; BATISTA, R. B.; BARROS, E. F. de; MOREIRA, M. A. R. Caracterização da via das lipoxigenases em plantas de soja resistentes e suscetíveis a Diaphrte phaseolorum f. sp. meridionalis, agente causal do cancro-da-haste. Revista Brasileira de Fisiologia Vegetal, Campinas, v. 13, n. 3, p. 316-318, 2001.
SILVA, T. V.; RESENDE, E. D. de; VIANA, A.P.; ROSA, R. C. C.; PEREIRA, S. M. de F.; CARLOS, L. de A.; VITOROZI, L. Influência dos estádios de maturação na qualidade do suco do maracujá-amarelo. Revista Brasileira de Fruticultura, Jaboticabal, v. 27, n. 3 p. 472-475, 2005.

SILVEIRA, N. S. S. da; MICHEREFF, S. J.; SILVA, I. L .do S. S. da; OLIVEIRA, S. M. A de.Doenças fúngicas pós-colheita em frutas tropicais: patogênese e controle. Caatinga, Mossoró, v. 18, n. 4, p. 283 299, 2005.

SOUZA JÚNIOR, I. T.; SALES, N. L. P.; MARTINS, E. R. Efeito fungitóxico de óleos essenciais sobre o Colletrotrichum gloeosporioides, isolado do maracujazeiro-amarelo. Biotemas, Trindade, v. 22 , n.32, p. 77 - 83, 2009

SOUZA, L. S. S.; SOARES, A. C. F. Efeito in vitro do extrato de nim (Azadirachta indica). Revista Brasileira de Agroecologia, Brasília, n. 2, p. 4393 - 4396, 2009

SOUZA, M. A. A.; SOUZA, S. R.; VEIGA JR., V. F.; CORTEZ, J. K. P. C.; LEAL, R. de S.; DANTAS, T. N. C.; MACIEL, M. A. M. Composição química do óleo fixo de Croton cajucara e determinação das suas propriedades fungicidas. Revista Brasileira de Farmacognosia, Curitiba, v. 16, p. 599-610, 2006.

VEIGA JÚNIOR, V. F.; PINTO, A. C. O gênero Copaifera L. Química Nova, São Paulo, v. 25, n. 2, p. 273-286, 2002.

VEIGA JR., V. F.; PATITUCCI, M.L.; PINTO, A.C. Controle de autenticidade de óleos de copaíba comerciais por cromatografia gasosa de alta resolução. Química Nova, São Paulo, v.20, n.6, p. 612-615, 1997.

VENTUROSO, L. dos R. Extratos vegetais no controle de fungos fitopatogênicos à soja. 2009. 99 f. Dissertação (Mestrado em Agronomia - Área de Concentração Produção Vegetal) -Universidade Federal da Grande Dourados, Dourados, 2009.

WANG, J.; LIA, J.; CAO, J.; JIANG, W. Antifungal acticities of neem (Azadirachta indica) seed kermel extracts and postharvest disease in fruits. African Journal of Microbiology Research, Nairobi, v. 4, n. 11, p. $1100-1104,2010$. 